\title{
Perspective
}

PERSPECTIVE Actualité en histoire de l'art

Comptes rendus | 2013

\section{Alexandra Midal, Design, l'anthologie : 1841-2007, Paris, Cité du Design, 2013.}

Étienne Tornier

\section{(2) OpenEdition}

Journals

Édition électronique

URL : http://journals.openedition.org/perspective/6599

DOI : 10.4000/perspective.6599

ISSN : 2269-772

Éditeur

Institut national d'histoire de l'art

Référence électronique

Étienne Tornier, «Alexandra Midal, Design, l'anthologie : 1841-2007, Paris, Cité du Design, 2013. »,

Perspective [En ligne], Comptes rendus, mis en ligne le 28 juillet 2016, consulté le 01 octobre 2020

URL : http://journals.openedition.org/perspective/6599; DOI : https://doi.org/10.4000/perspective. 6599

Ce document a été généré automatiquement le 1 octobre 2020. 


\section{Alexandra Midal, Design, l'anthologie : 1841-2007, Paris, Cité du Design, 2013.}

Étienne Tornier

\section{RÉFÉRENCE}

Alexandra Midal, Design, l'anthologie : 1841-2007, Paris, Cité du Design, 2013. 
1 L'anthologie d'Alexandra Midal vient combler une importante lacune dans l'historiographie du design en France. Il s'agit du premier recueil de textes en langue française portant sur le design en tant que concept, pratique et discipline. Parus entre 1841 et 2007 en Europe et aux États-Unis, les quatre-vingt-quatorze textes que contient l'ouvrage ont, pour près de la moitié, fait l'objet de traductions. Design, l'anthologie fait le

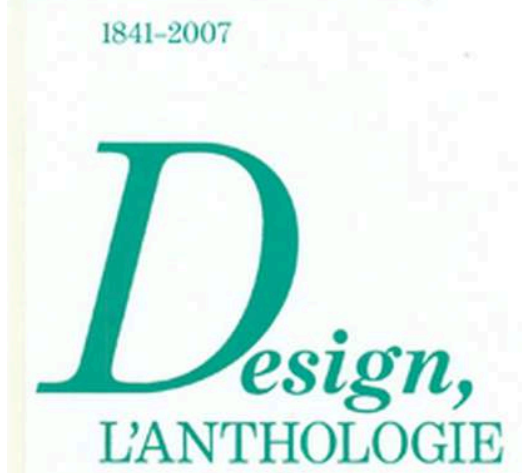
choix d'une chronologie large et de textes provenant presqu'exclusivement du champ du design (designer, fabricants ou critiques), mettant volontairement de côté les écrits exégétiques des sociologues et philosophes. En cela l'auteur s'inscrit dans la lignée de design readers publiés en Angleterre et aux États-Unis depuis les années 1970 (Design History. An Anthology, Cambridge, 1995 ; Carma Gorman (dir.), The Industrial Design Reader, New York, 2003 ; Grace Lees-Maffei et Rebecca Houze (dir.), The Design History Reader, New York, 2010) dont elle tire d'ailleurs un certain nombre de textes (en particulier: Tim Benton, Charlotte Benton et Dennis Sharp (dir.), Form and Function: A Source Book for the History of Architecture and Design, 1890-1939, Londres, 1975). Chaque texte est introduit par une brève présentation de leur auteur, guidant le lecteur dans la compréhension des textes, leur contexte historique et théorique. L'index particulièrement exhaustif constitue un outil pour faire dialoguer les textes entre eux, autour de problématiques transchronologiques (exposition, conception, goût, style...). D'un siècle à l'autre, les textes se font écho, à l'instar des célèbres «Ornement et crime » d'Adolf Loos (1908) et «Design et crime » de Hal Foster (2002). Si l'anthologie contient des textes fondateurs et donc incontournables pour tout étudiant en arts appliqués, de John Ruskin à Victor Margolin en passant par Henry van de Velde, Hermann Muthesius, Le Corbusier, Bruno Munari et Andrea Branzi, il intègre également des écrits méconnus (Catherine Beecher, "On the Construction of Houses ", 1846), révélant ainsi des points de vue jusque-là écartés par l'historiographie. L'accent mis sur la seconde moitié $d u x^{\mathrm{e}}$ siècle jusqu'aux années 2000 - période représentée les deux tiers des textes - permet de comprendre la place croissante du design, son évolution progressive comme discipline (voir à ce sujet la traduction salutaire du texte de Victor Margolin, «Design History and Design Studies », 2002) et nous ferait, a contrario, presque regretter que les périodes précédentes n'aient pas été aussi densément traitées (seulement trois textes antérieurs à 1895).

À rebours d'une histoire du design qui met l'accent sur les formes, les techniques et les matériaux, l'anthologie inscrit le design non pas dans une histoire des styles, mais bien dans une activité théorique et critique qui dépasse largement les frontières de son objet. L'absence de toute catégorisation ou découpage apparaît comme un véritable parti pris, pied de nez à l'historiographie du design depuis Nikolaus Pevsner et son Pioneers of the Modern Movement (Londres, 1936). Comme le souligne justement Alexandra Midal, le lecteur est laissé «à sa propre construction», un puzzle tant 
historique qu'historiographique, ce que nombre d'ouvrages de ce type ne permettent guère. 